\title{
Knowledge Inventory Management Using Actuarial Method
}

\author{
Yunpeng Wu, Lu Liu and Yin Guo \\ School of Economics \& Management, Beihang University, Beijing 100083, P.R. China \\ foxwu718@gmail.com liulu@buaa.edu.cn erica0201@126.com
}

\begin{abstract}
Knowledge inventory management is nowadays central issue as knowledge management becomes vital for organizations. Knowledge inventory management involves acquiring, retaining, deploying, idling, and abandoning technologies. Managers must make investment decisions about which technologies should be involved into inventory for future usage. Optionspricing model (OPM) has been widely accepted to make investment decisions. An alternative technology is regarded as an option to switch technologies to deal with future contingencies. This paper studies another kind of knowledge inventory problem which OPM is sort of inefficient to deal with. An organization might be forced to invest in some technology in the future because of some specific incident occurs, thus option is replaced by obligation. The characteristics of this kind of problem are portrayed and we show why OPM is not applicable. We treat the specific incident as an insurance accident to organizations and initial investment in some technology as insurance fee which can cover the loss when accident occurs. We use actuarial model to analyze the problem and give the evaluation methods in different conditions.
\end{abstract}

Keywords: Knowledge management, Value analysis, Value estimation, Strategic enterprise management, Value modeling

\section{INTRODUCTION}

Organizations are facing the challenge of maintaining appropriate knowledge inventories [1]. They need sufficient knowledge to deal with the changing environment and keep core competences. This requirement, however, is not easy to satisfied and still problematic. Since situations or proper responses are numerous and shifting, it is even harder to specify and realize the optimal inventory level of knowledge. By the time knowledge is needed, it is too late to gain it; before knowledge is needed, it is hard to specify precisely what knowledge might be required or useful. It is necessary to create inventories of competences that might be used later without knowing precisely what future demands will be [1].

Knowledge inventory management involves acquiring, retaining, deploying, idling, and abandoning technologies over time. The most important decision that managers have to make is which technology may be most appropriate for current and future use considering of flexibility and uncertainty [2]. Technology may be idled and maintained until there is a need to switch technologies. Among a stream of 
literatures, Kulatilaka and others has addressed the questions using real option theory which portrayed investments in alternative technologies as real option purchases and subsequent changes in the technology-in-use as option exercise decisions [3-5]. All these literatures see the alternative technologies as option which can be evaluated. If option value is higher than the cost of alternative technology, investment is favorable than wait or abandon, otherwise not.

This paper studied another kind of knowledge inventory problem which real option approach is sort of inefficient to deal with. An organization might face an accident that will happen in the future definitely, but the time of incurrence is uncertain. If it did occur, investment must be exercised. For example, a DVD assembler without core technologies will be charged patent fee at sometime in the future and have to pay for it to survive. Another good example is that Chinese state-owned concerns have to follow the government's instruction and invest in some technology although it is not favorable for the company, which is different from developed countries. Under this situation, organizations can have two strategies: a) invest in some specific technology in advance for preparation. b) Do nothing until the accident happens. There are three points that differentiate between this kind of problem and those can be addressed using real option approach:

1. Accident will happen definitely in the future but not at a definite day, so there is no maturity day needed in real option model.

2. When an accident happens, there is no right to choose but an obligation. The organization has to invest in some technology.

3. Investing into a specific technology in advance may not bring any profit to organizations. Nevertheless, if it could reduce the contingent loss brought by the accident then it is worth investing.

Considering these differences, we need another method to address this kind of problem. Risk management provides us a good perspective and we can use actuarial models to help us.

This paper is dedicated to frame the knowledge inventory problem. Departing from previous research based on real option theory, we explore the problem from insurance perspective. The first section introduces the background of knowledge inventory management and the unique characteristics of the problems this paper learned. The second section reviews some literatures in knowledge inventory management. The following section presents three investment strategies under different situations using insurance actuarial technologies. We give the solutions of how to make decisions. Then we discuss some major implications for future research.

\section{LITERATURE REVIEW}

Although knowledge inventory is becoming the major value driver for industries [6], knowledge inventory management is still a complex and hard issue an organization has to manage. Determining the variety and depth of knowledge to be added to the knowledge inventory is filled with potential pitfalls [1]. Knowledge 
inventory, also known as intellectual capital, is classified into three categories which is widely accepted: (i) human, (ii) structural, and (iii) customer or relationship capital. Only structural capital, which is owned by the firm and is assumed not to be reproduced and shared, is regarded as the best approximation of intellectual capital [7]. Since more and more uncertainties bring risks to technology investment, even simple knowledge inventory problems become challenging as managers attempt to think about the future and interactions among technologies [2]. Making investment decisions need to identify and value each intellectual capital and quantitative analysis need to change its methodology. Along with original DCF method being unable to deal with investment decision under uncertainty, real option method plays an important role to help decision makers analyzing investment. R\&D investment including knowledge inventory management has been a major focus in the real-option literatures. Dixit and Pindyck studied investment under uncertainty [8]. Peppard and Rylander have shown how intellectual capital can be identified and measured [9]. Bose and Oh combined real options and intellectual capital to incorporate the realoptions logic into the analysis and evaluation of intellectual capital [10]. Schwartz and Trigeorgis include classical readings where real options have been applied in several investment projects to account for the value of flexibility where traditional net present value (NPV) is unable to [11]. Some AI related technology like fuzzy set approach is also incorporate into real option analysis [12]. However, some literatures criticized that real option theory is sort of inefficient dealing with knowledge inventory analysis recently. Andrikopoulos reviewed and summarized the restrictive modeling assumptions real option theory need and figure out those factors hinder the adoption of this methodology [13]. We can see from these papers that OPM should not be the only method to analyze knowledge inventory management problems. In recent researches, researchers start to focus on performance level of different intellectual capital to make the value analysis. Chu etc give an empirical study of ITRI which associate the components of the intellectual capital with the value/performance of ITRI to investigate the real value of IC [14]. Ghosh and Wu examine two issues: financial analysts' investment recommendations when faced with different combinations of performance levels and the role of financial and IC measures with different performance levels and holding periods for the investment on analyst's recommendations [15]. Carlucci and Schiuma use AHP method to propose the knowledge assets value creation map to visualize and analyze the cause-and-effect relationships linking knowledge assets with company's performance [16]. Those literatures give different results and solutions to estimate the value of knowledge inventory (IC) which in turn help knowledge inventory management issues at some extend. However, all these works focus on how the value can be identified and created brought by knowledge inventory, that is, how they can make profit. The concentration of this aspect leads to ignorance that knowledge inventory also helps alleviating lost. To recognize this effect, some new methods should be applied either. 


\section{ACTUARIAL MODEL}

To keep it simple, some assumptions are indispensable for the model so that we could focus on the nature of the problem.

1. Accident will incur in the future but not a definite day as we point out above. The amount of the contingent loss brought by the accident can be estimated. The probability of the incurrence can be estimated too.

2. Investing in some specific technology initially will cover the whole loss if the accident incurs. That means there is no extra expense needed when it happens.

3. Every technology has its lifecycle. Investment in a technology will bring no returns after the technology has ended its lifecycle.

4. The loss distributions at any time during $n$ years are identical.

Now we can map this kind of problem to an n-year death insurance problem. 1) According to assumption 1, the incident can be treated as insurance accident. We don't know when it will occur, but there should be loss if it occurs. The contingent loss of the accident is stochastic from view of initial time point, which can be represented by a continuous random variable " $X$ ". 2) If the organization invests into a specific technology at current time, the cost is deterministic, noted by "a". The initial investment can be regarded as insurance fee because when accident occurs the organization doesn't have to pay the cost any more as if the loss would have been compensated by insurance company. 3) Since we always focus on a limited time period, we treat the lifecycle of the specific technology as the term of insurance according to assumption 3 . It is reasonable because the assumption guarantees that the initial investment as insurance fee will not work beyond the lifecycle period and just waste if the accident does not incur during the term.

We define $T(0)$ as the length from current time to some time in the future when accident happens, thus $T(0)$ is a random variable.

Let $F_{0}(t)=P[T(0) \leq t], t \geq 0, \mathrm{~F}$ is cumulative distribution function of $\mathrm{T}(0)$ according to assumptionl. In this model, $F$ represents the probability that accident will incur within $\mathrm{t}$. Another form of the expression is:

$$
S_{0}=1-F_{0}(t)=P[T(0) \geq t], t \geq 0
$$

The characteristics of $S$ are as follows:

1. $S_{0}(0)=1$ Accident will incur only in the future, so there is no uncertainty at current time.

2. $S_{0}(\infty)=0$ It is impossible that time period from current time to the time accident happened is longer than $\infty$. Accident will incur definitely.

3. $S_{0}(t)$ is a decreasing function.

4. $S_{0}(t)$ is usually a continuous function and derivable. 


\subsection{Payment Incurrence until the End of Year}

First we assume that if the accident happens during the period from $t$ to $t+1(t=1,2$, $3 . .$.$) , the concerning cost will be paid by the end of the year, which can be described$ as Figure 1 shows:

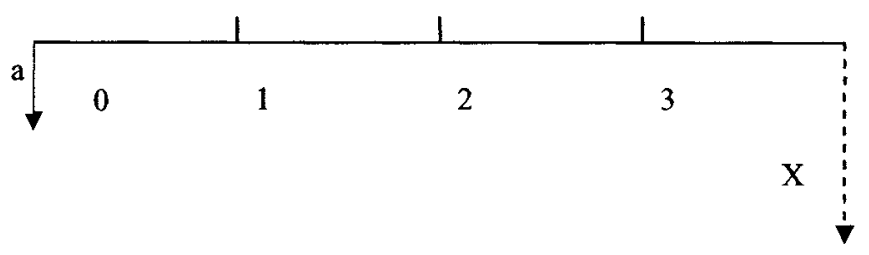

Figure 1. Knowledge Inventory Problem Model

We note ${ }_{t \mid 1} q_{0}=P[t<T(0) \leq t+1](t \geq 0)$, then we have the actuarial value of the insurance:

$$
\begin{aligned}
& A=\sum_{k=0}^{n-1} v_{k ! 1}^{k+1} q_{0} E(X)=\sum_{k=0}^{n-1} v^{k+1}\left[F_{0}(k+1)-F_{0}(k)\right] E(X) \\
& =\sum_{k=0}^{n-1} v^{k+1}\left[S_{0}(k)-S_{0}(k+1)\right] E(X)
\end{aligned}
$$

Where:

$X=$ the loss of accident. $\mathrm{X}$ is a random variable

$E(X)=$ expectation of $\mathrm{X}$

$v^{k}=$ discounted rate from period $\mathrm{k}$ to period 0

$n \quad=$ lifecycle of the technology $(\mathrm{n}=1,2,3 \ldots)$

The actuarial value means to make sure that the loss caused by accident could be secured totally, organization should invest " $A$ " at current time because the present value of the contingent cash flow is $A$. We then could compare the actuarial value with the definite investment at initial and make decision according to the following equation:

$$
R=a-A
$$

If $R>0$, organization will not invest but wait because the actuarial value is less than the cost of current time which means it is not worth investing " $a$ " to secure a smaller risk. If $R<0$, the investment will secure a bigger risk, then the organization could cover the contingent loss by preparing in advance. If $R=0$, then either choice is good enough to decision maker if he is risk neutral. 


\subsection{Payment Incurrence at Accident Time}

For some reasons, when the accident happens, the payment has to be made immediately instead of waiting until the end of the period to maintain operation. This can be portrayed as Figure 2 shown.

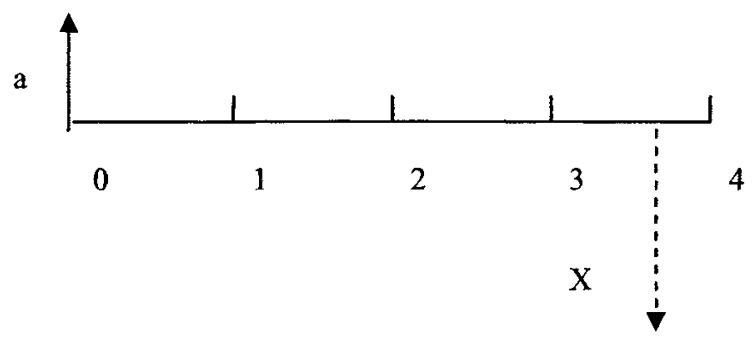

Figure 2. Knowledge Inventory Investment at Any Time

We must find the probability of occurrence in infinitesimal time period to calculate the actuarial value of the insurance, that is:

$$
\mu_{x}=\lim _{d x \rightarrow o} \frac{P[x<T(0) \leq x+d x \mid T(0)>x]}{d x}
$$

The relationship between $\mu_{x}$ and $S_{0}(t)$ is shown as follows:

$$
\mu_{x}=\lim _{d x \rightarrow 0} \frac{S_{0}(x)-S_{0}(x+d x)}{S_{0}(x) d x}=\frac{-S_{0}^{\prime}(x)}{S_{0}(x)}
$$

Considering the probability that accident incur between $t$ and $t+d t$, it is $S_{0}(t) \mu_{t}$. Now we can calculate the actuarial value of the risk:

$$
A=\int_{0}^{n} S_{0}(t) \mu_{t} E(X) v^{t} d t
$$

We can compare the definite cash flow of current time with the actuarial value and the same conclusion can be drawn as discussed above.

\subsection{Deferring Investment}

An organization can make investment decision according to the result from actuarial analysis. If the actuarial value is larger than actual cost of current time, investment is the best choice. But sometimes the probability of incurrence may be very small in the first a few years, Also an organization may not have enough money to invest at right time especially for medium and small company which always lack of 
cash. Should they keep waiting until they can afford the investment cost? This problem is shown as Figure 3:

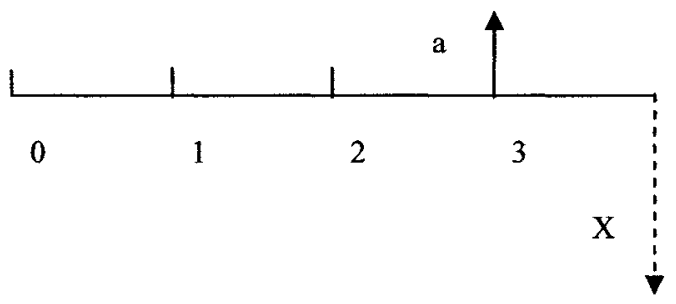

Figure 3. Deferring Knowledge Inventory Investment

If the organization determines to defer the investment to the end of $T$ year, then the actuarial value from 0 to $T$ is lost but capital time value can be achieved. First we can calculate the actuarial value under such circumstance:

$$
A=\sum_{k=0}^{T}{ }^{k+1}\left[S_{0}(k)-S_{0}(k+1)\right] E(X)
$$

Second we calculate the capital time value:

$$
a^{\prime}=\sum_{i=1}^{T} a r /(1+r)^{r}
$$

Where:

$\mathbf{r}=$ risk free interest.

Then $R=a^{\prime}-A$. If $R>0$, the organization will invest at $T$ because the value of the discounted cumulative interest return is higher than the actuarial value. If $R<0$, Investment at current time is superior. If $R=0$, either choice would be indifferent to another.

\section{DISCUSSION}

This study has modeled a framework to solve a kind of knowledge inventory management problems, but still some points are unclear and not elaborate in this article. Firstly, the insurance term which mapped to technology lifecycle is hard to determine. Different technologies have different lifecycles and even the same technology may have variable lifecycles if deployed in different organizations which varies from scale to industry. As the model indicates, the longer we set time period, the larger actuarial value we could get which means the earlier investment is more "profitable". On the other hand, technology races accelerate technology eliminating so the term should be less to reflect accurate actuarial value of risk. The dilemma 
often puzzles executives and there may be no former experience can be followed. Defining a suitable term is a complex and hard work.

Secondly, we assume interest rate is constant during time period we consider, which is not always true in actual world. Concerning interest rate, the time structure and risk structure should be emphasized. According to the time structure, the spot rate should be different among various maturities; the risk structure demonstrated that the rates of securities with different risk levels should be different. Longer period securities tend to have higher rate of return. So the required rate of return concerning the considered project should be decided according to its lifecycle and the random factors.

Finally, the contingent loss is not easily to estimate and the distribution is unclear because of lack of samples. Delphi method could be applied to estimate the expected value of the contingent loss. Extreme value theory (EVT) could gain good result to estimate too. It is a risk-measurement tool under extreme market condition which would help executives to deal with small sample problems, thus better decisions can be made.

\section{ACKNOWLEDGEMENTS}

The research is supported by the National Natural Science Foundation of China under Grant No.70671007 and the PhD Program Foundation of Education Ministry of China under Contract No. 20040006023.

\section{REFERENCES}

1. D.A. Levinthal and J.G. March, The myopia of learning, Strategic Management Journal. Volume 14, Number S2, pp.95-112, (1993).

2. K.D. Miller, Knowledge inventories and managerial myopia, Strategic Management Journal. Volume 23, Number 8, pp.689-706, (2002).

3. N. Kulatilaka and A.J. Marcus, General formulation of corporate real options, Research in Finance. Volume 7, pp. 183-199, (1988).

4. N. Kulatilaka and L. Trigeorgis, The general flexibility to switch: real options revisited, International Journal of Finance. Volume 6, pp.778-798, (1994).

5. N. Kulatilaka, The value of flexibility: a general model of real options (Praeger: Westport, 1995).

6. H. N. Rudež and T. Mihalič, Intellectual capital in the hotel industry: A case study from Slovenia, International Journal of Hospitality Management. Volume 26, Number 1, pp. 188-199, (2007).

7. A. Riahi-Belkaoui, Intellectual capital and firm performance of US multinational firms: a study of the resource-based and stakebolder views, Journal of Intellectual Capital. Volume 4, Number 2, pp.215-26, (2003).

8. A. Dixit and R. Pindyck, Investment under uncertainty (Princeton University Press: New Jersey, 1994). 
9. J. Peppard and A. Rylander, Using an intellectual capital perspective to design and implement a growths strategy: the case of APION, European Management Journal. Volume 19, Number 5, pp.510-525, (2001).

10. S. Bose and K-B. Oh, An empirical evaluation of option pricing in intellectual capital, Journal of Intellectual Capital. Volume 4, Number 3, pp.382-395, (2003).

11. E.S. Schwartz and L. Trigeorgis., Real Options and Investment under Uncertainty, Classical Readings and Recent Contributions (MIT Press: Cambridge, Massachusetts, 2004).

12. J. Wang and W.-L. Hwang, A fuzzy set approach for R\&D portfolio selection using a real options valuation model, Omega. Volume 35, Number 3, pp.247-257, (2007).

13. A. Andrikopoulos, The Real-Options Approach to Intellectual Capital Analysis: A Critique, Knowledge and Process Management. Volume 12, Number 3, pp.217-224, (2005).

14. P. Chu, Y. Lin, H. Hsiung, and T. Liu, Intellectual capital: An empirical study of ITRI, Technological Forecasting \& Social Change. Volume 73, Number 7, pp.886-902, (2006).

15. D. Ghosh and $\mathrm{A}$. Wu, Intellectual capital and capital markets: additional evidence, Joumal of Intellectual Capital. Volume 8, Number 2, pp.216-235, (2007).

16. D. Carlucci and G. Schiuma, Knowledge assets value creation map assessing knowledge assets value drivers using AHP, Expert Systems with Applications. Volume 32, Number 3, pp.814-821, (2007). 